\title{
Nota
}

\section{LA INSTRUCCIÓN «ECCLESIAE SPONSAE IMAGO» SOBRE EL «ORDO VIRGINUM». EL ESTADO DE VIRGINIDAD EN EL SIGLO XXI}

Fecha de recepción: 4 de septiembre de 2019

Fecha de aceptación y versión final: 8 de octubre de 2019

RESUMEN: Ecclesiae Sponsae Imago (=ESI) es, hasta el momento, el documento más largo y detallado sobre el Ordo virginum que la Iglesia nos ha dado desde el Concilio Vaticano II. La Instrucción es un tipo de documento magisterial que provee de claridad a leyes recientes, especialmente aquellas que pudieran ser de interpretación vaga o discutida. ESI clarifica, el tenor de vida de la virgen consagrada, establece criterios más claros sobre el discernimiento de las vocaciones, considera la importancia de la formación y facilita un esquema de cómo debe ser, describe la relación de la consagrada con la diócesis, y habla sobre la salida del Ordo virginum. ESI transmite la idea de que la llamada a la virginidad consagrada es una verdadera vocación que merece ser tomada en serio.

PALABRAS CLAVE: virgen; admisión; discernimiento; formación; vocación; diócesis.

\section{The Instruction "Eclesiae Sponsae Imago" on the "Ordo Virginum». Virginity State in the XXI Century}

ABSTRACT: Ecclesiae Sponsae Imago (=ESI) is so far the longest and more detailed document on the Ordo virginum that the Church has given us since the second

"Licenciada en Derecho Canónico: gortegagavara@gmail.com 
Vatican Council. To start with, the Instruction is a type of magisterial document which provides clarity on earlier existing laws, especially ones which may have been vague or may have had disputed interpretations. ESI clarifies the tenor of a consecrated virgin's way of life, establishes some clearer criteria for the discernment of vocations, considers the importance of formation and gives an outline of what this should look like, and describes the relationship between a consecrated virgin to her diocese. ESI communicates the idea that a call to consecrated virginity is a real vocation that's worth taking seriously.

KEY WORDS: virgin; admission; discernment; formation; vocation; diocese.

\section{PLANTEAMIENTO}

El 4 de julio de 2018 la Congregación para los Institutos de Vida Consagrada y Vida Apostólica presentó la instrucción Ecclesiae Sponsae Imago (=ESI) sobre el Ordo virginum, que había sido aprobada por el papa Francisco un mes antes ${ }^{1}$. Esa Instrucción ha venido a desarrollar la breve regulación del Código de Derecho Canónico y de los preliminares del Ritual de consagración de vírgenes de 1970.

La Instrucción del Ordo virginum es el resultado de una amplia consulta, una obra sinodal en la cual participaron obispos, vírgenes consagradas y expertos de todo el mundo, para poner de relieve las especificidades y las riquezas de esta forma de vida consagrada.

El documento explica que virginidad, esponsalidad y maternidad son tres perspectivas que permiten descubrir la experiencia espiritual de las vírgenes consagradas; son dinámicas espirituales realizadas una en la otra y asentadas en las coordenadas fundamentales de la vida bautismal.

La Instrucción, que cuenta con 115 números, parte de una introducción general y se desarrolla a lo largo de tres capítulos, para terminar con una conclusión.

El primer capítulo, que se refiere a la vocación y el testimonio del Ordo virginum, aborda el fundamento bíblico de la virginidad consagrada; el carisma y la vocación; el propositum, la consagración y el estado de vida; y su fisonomía espiritual.

${ }^{1}$ CIVCSVA, Instrucción Ecclesiae Sponsae Imago, 8 junio 2018, http://www.vatican. va/roman_curia/congregations/ccscrlife/documents/rc_con_ccscrlife_doc_20180608_ istruzione-ecclesiaesponsaeimago_sp.html (consultada 20 de agosto de 2019). 
El segundo, relativo a la configuración del Ordo virginum en las iglesias particulares y en la Iglesia universal, se detiene en la responsabilidad del obispo, que puede contar con la ayuda de un delegado o delegada; en el arraigo y la comunión de las vírgenes con su diócesis; en el derecho de asociación y pertenencia a otros grupos eclesiales; en la opción por la vida común; en la permanencia y traslado de la virgen a otra diócesis; en el modo de tránsito a un Instituto de Vida Consagrada o Sociedad de Vida Apostólica; y en el proceso de salida o dimisión.

El tercero aborda el discernimiento vocacional y la formación para el Ordo virginum, y abarca el compromiso del discernimiento y la formación; las fases y duración del itinerario formativo previo: propedéutico y teológico; los requisitos y criterios de discernimiento: edad mínima, ausencia de nupcias o concubinato, la madurez humana que puede ser verificada con el consentimiento de la candidata con el recurso a expertos en competencia psicológica; la madurez espiritual; los escrutinios y admisión a la consagración por el obispo; y la formación permanente de las ya consagradas.

Termina con una oración a la Virgen, modelo de las vírgenes consagradas, a modo conclusivo.

Este documento, largamente esperado por las vírgenes consagradas, adopta la forma jurídica de una Instrucción, que completa, desarrolla y especifica el modo de aplicación de cuestiones que habían sido mencionadas, pero no clarificadas del todo, ni por el Código de Derecho Canónico de 1983, ni por los prenotandos del Ritual de consagración de 1970. Casi 50 años después de la aprobación del Ritual contamos con una regulación completa de esta forma de vida, que requería una configuración jurídica tras su resurgimiento ${ }^{2}$.

\section{ANTECEDENTES. REGULACIÓN CODICIAL DE 1983}

El punto de partida es la regulación que el Código de Derecho Canónico realiza de la materia en su canon 604 , que ha sido desarrollado por la Instrucción.

2 Francisco de Borja Vizmanos, Las Vírgenes cristianas de la Iglesia primitiva (Madrid: BAC, 2009), 411, 417. 
1. «A estas formas de vida consagrada se asemeja el orden de las vírgenes que, formulando propósito de seguir más de cerca a Cristo, son consagradas a Dios por el Obispo diocesano según el rito litúrgico aprobado, celebran desposorios místicos con Jesucristo, Hijo de Dios y se entregan al servicio de la Iglesia».

2. «Las vírgenes pueden asociarse, para cumplir su propósito con mayor fidelidad y para realizar, mediante la ayuda mutua, el servicio a la Iglesia congruente con su propio estado».

Es un canon descriptivo, que especifica que el Ordo virginum se asemeja a las formas de vida consagrada que, según el código, están integradas por los Institutos de Vida Consagrada (institutos religiosos e institutos seculares) y por las Sociedades de Vida Apostólica. No forma parte de los Institutos de Vida Consagrada al no profesar los consejos evangélicos, y tratarse de una vida personal no comunitaria, pero forma parte de la vida consagrada; se trata de un orden en el sentido de grupo, no de orden religiosa, instituto o congregación.

A la hora de profundizar en el sentido del canon 604, la doctrina incide en la consideración del ordo como grupo o sociedad con peculiaridades propias, situando jurídicamente a las vírgenes en un estado público en la Iglesia ${ }^{3}$. Se afirma que las vírgenes conservan su condición secular, siendo la secularidad una forma de testimoniar en el mundo el sentido de la virginidad consagrada.

Se ha planteado a nivel doctrinal si son o no una forma de vida consagrada, la mayoría de la doctrina concluye que, si bien al canon 604 le son de aplicación las normas comunes a los Institutos de Vida Consagrada, las vírgenes no profesan los consejos evangélicos, sino que únicamente hacen propósito de castidad ${ }^{4}$.

3 Carmen Álvarez-Alonso, "Orden de las Vírgenes", en Diccionario General de Derecho Canónico, dir. Jorge Otaduy, Antonio Viana, Joaquín Sedano (Cizur Menor: Thomsom Reuters - Aranzadi, 2012), 5:745-747.

4 Tomás Rincón-Pérez, "Comentario al canon 604", en Comentario Exegético al Código de Derecho Canónico II, dir. Angel Marzoa, Jorge Miras, Rafael Rodríguez-Ocaña (Pamplona: Eunsa, 1996), 1497-1498. Como han destacado otros, el significado del término latino accedere, es «ir hacia, acercarse o aproximarse», término que el código traduce por «se asemeja»: «La semejanza es con las otras formas de vida consagrada: Institutos de vida religiosa, Institutos Seculares, Ermitaños»: Aitor Jiménez, "El Ordo Vírgenes consagradas a la luz del código vigente", Commentarium pro religiosis et missionaris LXXV (1994): 225. 
Del canon 604 pueden destacarse las siguientes notas:

a) Realizan el propósito de seguir más de cerca a Cristo por medio de un propósito de castidad que, sin ser voto religioso, es público.

La consagración de vírgenes no es inferior a la de los Institutos de Vida Consagrada; de hecho, las religiosas también pueden ser consagradas según el ritual de vírgenes ${ }^{5}$. La diferencia estriba en que son consagradas por Dios a título personal y viven en soledad, sin contar con la ayuda de una comunidad estable y de una estructura jerarquizada.

b) Celebran desposorios con Cristo.

La esponsalidad constituye el rasgo más inherente y esencial de esta forma de vida ya que son verdaderas esposas, de ahí que al recibir la consagración reciban los dos signos característicos del matrimonio: el anillo y el velo.

c) Son consagradas por el obispo.

Las vírgenes no se consagran, sino que son consagradas por el obispo diocesano que podrá delegar en otro obispo (auxiliar o titular), lo que nos dice otra característica esencial que es la diocesanidad, esto es, el quedar vinculadas a la diócesis después del rito de consagración en una ceremonia pública, preferiblemente en la catedral. Así pues, la consagración se produce normalmente en la catedral, mediante un rito litúrgico reformado según decretos del Concilio Vaticano II, aprobado por el episcopado de cada país y confirmado por la Sagrada Congregación para los Sacramentos y el Culto Divino.

d) Se entregan al servicio de la Iglesia.

La respuesta de la virgen emana de la llamada a llevar una vida esponsal que se materializa en el seguimiento de Cristo y en el servicio a su Iglesia. La virgen no es consagrada para sí misma, sino para ejercer los ministerios que, como esposa de Cristo, la Iglesia, tras su consagración, le confía.

Nada dice el canon 604 acerca de los requisitos de admisión (una de las cuestiones más debatidas de los últimos años), que sí eran mencionados por los prenotandos de ritual pero que requerían un desarrollo más detallado desde el punto de vista normativo, que la Instrucción ha venido a aclarar.

\footnotetext{
${ }^{5}$ Ritual de Consagración de vírgenes, prenotando 4, Madrid 1979.
} 


\section{LOS REQUISITOS DE ADMISIÓN EN LOS PRELIMINARES DEL RITUAL DE CONSAGRACIÓN Y EN LA INSTRUCCIÓN}

Era en los preliminares del ritual de consagración de vírgenes donde podían encontrarse los requisitos que se precisan para la admisión de las vírgenes que viven una vida seglar:

a) «Que nunca hayan celebrado nupcias y no hayan vivido pública o manifiestamente en estado opuesto a la castidad.

b) Que, por su edad, prudencia, costumbres probadas a la vista de todos, sean fieles en la vida casta y puedan perseverar dedicadas al servicio de la Iglesia y del prójimo.

c) Que sean admitidas a la consagración por el Obispo, Ordinario del lugar. Al Obispo corresponde establecer de qué modo y con qué condiciones las vírgenes seglares se obligan a abrazar perpetuamente la vida virginal ${ }^{6}$.

Estos requisitos han sido mantenidos y reafirmados por la Instrucción, que dice:

«La admisión requiere que por edad, la madurez humana y espiritual, y por la estima que disfruta en la comunidad donde está inserta, la candidata dé confianza de poder asumir de forma responsable los compromisos que derivan de la consagración.

Requiere que la persona nunca haya celebrado nupcias y no haya vivido pública y manifiestamente en un estado contrario a la castidad $»^{7}$.

Considero importante analizar estos requisitos de forma individualizada y también en su conjunto.

\subsection{NO HABER CONTRAÍDO NUPCIAS NI VIVIDO PÚBLICA O MANIFIESTAMENTE EN ESTADO OPUESTO A LA CASTIDAD}

\subsubsection{No haber contraído nupcias}

En primer lugar, se pide a la aspirante no haber contraído matrimonio previamente, con independencia de la validez o invalidez del mismo, por lo que considero que este requisito hace referencia a haber celebrado nupcias, tanto civiles, como canónicas.

${ }^{6}$ Ritual de Consagración de vírgenes, prenotando 5, Madrid 1979.

7 Ecclesiae Sponsae Imago 84, Roma 2018. 
Por lo tanto, provenir de un previo matrimonio declarado inválido, en cuanto que es una situación pública y estable con deseo de permanencia, tiene su peso para el derecho canónico y es un obstáculo para ser virgen consagrada.

En el caso de que el matrimonio hubiera sido disuelto por rescripto pontificio, por ser un matrimonio no sacramental, o incluso por ser un matrimonio rato y no consumado, la mujer - aun teniendo integridad física- no podría acceder al Ordo virginum, ya que su matrimonio fue válido, aunque por concesión graciosa del romano pontífice, en virtud del poder de las llaves, se haya disuelto con posterioridad.

\subsubsection{No haber vivido pública o manifiestamente en estado opuesto a la castidad}

Este es un tema difícil de tratar, que ha generado cierta controversia y que ha sido interpretado durante bastante tiempo de forma extensiva, equiparándolo a integridad física ${ }^{8}$.

Sin embargo, la Instrucción Ecclesiae Sponsae Imago lo ha clarificado señalando que no constituye un requisito determinante en ausencia del cual (sine qua non) sea imposible admitir a la consagración.

«[...] En este contexto se tendrá presente que la llamada a dar testimonio del amor virginal, esponsal y fecundo de la Iglesia a Cristo, no se reduce al signo de la integridad física, y que haber vivido ejemplarmente la castidad, aunque es de gran importancia en orden al discernimiento, no constituye requisito determinante en ausencia del cual sea imposible admitir a la consagración» $(E S I, 88)$.

Hay que comenzar recordando que tanto impedimentos como requisitos de admisión son leyes que exigen interpretación estricta, según el canon 18. En otras palabras, los requisitos son lo que son, y el ritual -y la instrucción- dicen lo que dicen; y, según el canon 10 de CIC «se han de considerar invalidantes o inhabilitantes solo aquellas leyes en las que expresamente se establece que un acto es nulo o una persona es inhábil».

8 Raymond Leo Burke, "Lex orandi, lex credendi. El rito de la consagración y la vocación de la virginidad consagrada en el mundo", en Virginidad consagrada en el mundo. Un don para la Iglesia y en la Iglesia, en Actas del III Congreso Internacional del Orden de las Vírgenes celebrado en Roma, mayo 2008, ed. Lourdes Grosso (Madrid: Edice 2010), 50. 
"Haber vivido de forma pública o manifiestamente en contra de la castidad» no se refiere a la posibilidad de prueba en el fuero externo, sino a la publicidad, habitualidad y divulgación de la situación. En el caso que nos ocupa, alcanzaría a los concubinatos, convivencias de hecho more uxorio, supuestos en que esta situación haya devenido estado, etc., por lo que no incluye de suyo episodios, hechos puntuales, acaecidos dentro de la estricta privacidad de la persona, aunque verificables en el fuero externo por la declaración de la persona con la que se ha tenido la relación sexual.

Respecto a la tendencia a identificar este requisito con integridad física, ya en una alocución al Congreso internacional del Ordo Virginum celebrado en Roma en junio de 1995, se señaló la importancia del himen, del que carecen los animales y que solo afecta a la sexualidad humana. Esta visión considera que:

«[...] la virginidad no es atribuida al hombre más que de una manera aproximada, imperfecta, en el plano creado: solo pertenece verdaderamente, a la mujer [...] los hombres consagrados son llamados ascetas, eremitas o monjes, nunca vírgenes»⿳.

Otorgando gran valor a la virginidad física, a la integridad, sin embargo, me parece que es una mala interpretación derivada del platonismo, que marca la diferencia entre lo corporal y lo espiritual; la virginidad no se limita al solo no, sino que ella comporta un sí profundo en el orden esponsal ${ }^{10}$. El orden de las vírgenes como forma de consagración está reservado a las mujeres ya que ellas reflejan de forma especial la imagen de la Iglesia como esposa; la cualidad de esposa es mejor representada por la mujer, aunque todos los miembros de la Iglesia participen de esos desposorios $^{11}$.

Respecto al aspecto público del acto deshonesto, el cardenal R. L. Burke consideraba que, en algunos lugares, como Norteamérica, se

\footnotetext{
9 Janine Hourcade, Una vocación femenina recuperada: el Orden de las Vírgenes Consagradas (Salamanca: Secretariado Trinitario: 2003), 124-127.

10 Hourcade, 129.

11 Si bien esto es obvio desde el punto de vista antropológico, no deja de resultar sorprendente que ningún varón reclame para sí el reconocimiento de la virginidad en cuanto tal y que, cuando nos referimos al género masculino, solo se hable de celibato; celibato y virginidad se distinguen, pero pienso que son atributos atribuibles a ambos sexos y así lo mismo que hay mujeres célibes, hay hombres vírgenes por el reino de los Cielos y por Gracia de Dios.
} 
había producido cierta confusión respecto a la segunda parte de este requisito, y afirmaba que «los actos públicos se cometen con otra persona, y por tanto no cabe duda de que son conocidos por ésta, aunque solo sea un individuo» ${ }^{12}$.

Pese a la opinión del mencionado cardenal, es conveniente distinguir con claridad integridad física (voluntaria o involuntaria) con estado de virginidad, que refiere a estabilidad, permanencia, habitualidad, teniendo en cuenta que el requisito habla de estado opuesto a la castidad, no de integridad física.

No se puede identificar publicidad con fuero externo (lo que puede ser probado), pues en realidad la publicidad no tiene que ver con la prueba del hecho, sino con la condición de habitualidad, estabilidad, permanencia, que no alcanza a los episodios puntuales acaecidos en una habitación sin ninguna divulgación.

Distinto sería que hubiera habido una convivencia de hecho, una exhibición de la situación de forma manifiesta, o una forma de vida licenciosa alardeando de promiscuidad. En este caso, la candidata no cumpliría los requisitos, ante la posibilidad de producir escándalo en el pueblo de Dios, por el carácter público de la consagración; en esta situación, habría que encaminar a la mujer hacia otras formas de vida consagrada, encontrándose el obstáculo, no en el acto deshonesto, sino en haber tenido un esposo de hecho.

Pese a tratarse de una cuestión largamente debatida, la Instrucción Ecclesiae Sponsae Imago ha reiterado de modo claro que no hay inconveniente en que sea admitida al ordo (máxime si ha transcurrido tiempo prudencial, previo arrepentimiento, perdón de Dios y conversión de costumbres) una mujer que, de forma puntual, haya tenido caídas que no han constituido un estado civil o canónico (de hecho o de derecho).

\subsection{EDAD, PRUDENCIA Y COSTUMBRES}

En segundo lugar, «que por su edad, prudencia y costumbres probadas a la vista de todos puedan perseverar en su propósito de castidad y de seguimiento a Cristo durante toda la vida». Este requisito busca no solo el bien de la virgen sino el del pueblo de Dios, que en caso contrario pudiera quedar cuanto menos desedificado.

12 Burke, 50 . 
Me parece oportuno señalar que el propósito de castidad no se hace solo en el momento de prestarlo (in fieri), sino para vivirlo de forma continuada (in facto esse), y que las luchas no solo pueden haber sido previas a la consagración, sino que pueden ser posteriores.

Quiero incidir en ese aspecto, porque, como sucede con el consentimiento válidamente prestado en la ceremonia nupcial, la consagración es el punto de partida, no de llegada; en el trato que he mantenido con vírgenes consagradas, he observado que se incide mucho en el antes y, una vez consagradas, en ocasiones se dispersan y poco o nada se vuelve a saber de ellas.

\subsubsection{Edad}

Respecto a la edad sabemos que en la antigüedad eran consagradas niñas como el caso de santa Inés; sin embargo, no es así en la actualidad, ya que no se celebrará la consagración hasta que la candidata haya cumplido 25 años.

«En ningún caso se podrá iniciar el periodo propedéutico antes de cumplir los dieciocho años de edad; para la admisión a la consagración se deberá tener en cuenta la edad de casarse tradicional en la región y ordinariamente no se celebrará la consagración hasta que la candidata haya cumplido los veinticinco años de edad» $(E S I, 82)$.

Es una vocación, que por sus peculiares características requiere de una madurez afectiva; son mujeres formadas que en ocasiones han vivido este propósito en la privacidad hasta que descubrieron que su estado podía tener un reconocimiento eclesial.

«El Ordo virginum requiere más que en otras vocaciones una suficiente madurez humana y equilibrio psicológico. No porque sea una forma de vida selectiva, sino porque la mujer permanece sola en la dirección de su propia existencia» ${ }^{13}$.

Esta implica la capacidad de establecer relaciones sanas con hombres y mujeres, unida a una sana valoración del matrimonio y de la maternidad; la capacidad de integrar la sexualidad y orientar sus energías

${ }_{13}$ Paola Moschetii, El Ordo Virginum, germen de la vida cristiana (Salamanca: Secretariado Trinitario 2012), 145-147. 
afectivas; la capacidad para procesar sufrimientos y frustraciones; y un conocimiento realista de sí misma con sus talentos y límites (ESI, 87).

También se les exige madurez humana y en este sentido no podrán suponer una carga para la diócesis, sino que tendrán un medio de vida; en la mayoría de los casos desempeñarán su labor profesional en el ejercicio de un trabajo remunerado, en el campo de la enseñanza, de la sanidad, aunque también hay algunas en el ámbito judicial y empresarial ${ }^{14}$.

La virgen únicamente dispone para vivir de su trabajo y de su patrimonio, que deberá administrar con prudencia; de ello se deriva que, cuando llegue la enfermedad incurable o la ancianidad, tendrá los medios de los que pueden disponer otras personas no consagradas, como asilos y residencias. En definitiva, la virgen consagrada administra su salario, usa de sus bienes con libertad, promoviendo su formación, prestando ayuda a las obras de apostolado y caridad.

En ocasiones la diócesis puede encomendarles algún servicio pastoral de forma exclusiva, en cuyo caso recibirán el salario y prestación social oportuna con cargo a la diócesis como señala el canon 228, 1 CIC:

«Los laicos que sean considerados idóneos tienen capacidad de ser llamados por los Sagrados Pastores para aquellos oficios eclesiásticos y encargos que puedan cumplir según las prescripciones del derecho».

En conclusión, erradicado el afán de codicia, la virgen no ha de vivir angustiada por tener o no tener lo suficiente para vivir en sus últimos años, sino que confiará que el Señor le concederá lo necesario para su sustento.

\subsubsection{Prudencia}

Se les exige prudencia que les ayude a encontrar el camino justo para alcanzar el fin determinado, buen juicio y sensatez en el ordenar su vida para ser fieles a su consagración en sus hábitos, costumbres y forma de vida; no se trata de individualismo egocentrista, sino de personalismo.

La prudencia no solo implica evitar el mal, sino poner todos los medios a su alcance para el desarrollo de su vocación en el seguimiento más cerca de Jesucristo su Esposo; esta virtud le permitirá discernir

\footnotetext{
${ }^{14}$ Datos deducibles de contactos mantenidos con vírgenes consagradas de ámbito nacional.
} 
entre el bien y el mal y ordenar su vida a la unión esponsal con Cristo Jesús.

\subsubsection{Costumbres}

Igualmente tendrán que ser mujeres de santas costumbres verificadas en el día a día por el pueblo de Dios, por los fieles, por aquellos con quienes se cruzan, de modo que la virgen ofrezca garantías de perseverar en su propósito durante toda su vida.

Me refiero con la palabra "costumbre», a los hábitos y forma de vida que deben ser verificadas por el obispo, o su delegado antes de su consagración, para evitar posibles escándalos y perjuicio a la Iglesia.

\subsection{HABER SIDO ADMITIDAS POR EL OBISPO}

En tercer lugar, han de ser admitidas a la consagración por el obispo, ordinario del lugar, ante el cual prestan el propósito de castidad con un significado activo, entendido como intención de guardar castidad perfecta y de seguir fielmente a Cristo; el ritual habla de renovación, porque lo normal es que privadamente la aspirante ya lo haya prestado antes.

A efectos del orden de las vírgenes, el propósito sin la consagración posterior no supone en sí mismo nada, la virgen no se consagra, sino que es consagrada por la oración pronunciada sobre ella.

Ya en la antigüedad había dos clases de vírgenes: las que solo habían emitido el propósito y las que además habían recibido la consagración; unas y otras son vírgenes de la Iglesia, pero solo tenían la consideración de vírgenes consagradas las segundas.

\subsubsection{Discernimiento del obispo}

El discernimiento que lleva a cabo el obispo incluye aproximación, elaboración de un plan de formación, entrevistas o escrutinios, es decir, todo un proceso que culminará con la admisión y consagración de la candidata en una ceremonia presidida por él.

Es competencia del obispo la decisión final con relación a los actos de mayor importancia como: la admisión a la consagración; la adscripción en su diócesis de una consagrada que viene de otra; la dispensa de 
las obligaciones de la consagración; la aprobación de las directrices para la formación; la gestión económica de la actividad del Ordo virginum; el reconocimiento y la aprobación de los estatutos de las asociaciones de vírgenes consagradas (ESI, 50).

La candidata, en su primera aproximación, manifestará al obispo su intuición vocacional y le someterá su regula vitae, que debe incluir la participación en la Sagrada Eucaristía donde encontrará alimento y vigor; oración personal; el rezo de las Horas; alguna devoción mariana, que constituirá para ella el espejo donde mirarse y su misión apostólica (ESI, 99).

«Al elaborar la propia regla de vida, es importante ser ayudada por un padre espiritual. Después se somete al obispo o al delegado si la diócesis es grande y el obispo no puede ocuparse de todo personalmente» ${ }^{15}$.

Es un gesto de humildad y de entrega, no para estar controladas, sino para contar con la garantía de que lo se busca es hacer la voluntad de Dios; se sugiere que tengan un padre espiritual con el que hacer discernimiento, sobre todo teniendo en cuenta que faltan otros apoyos en su camino; estos acompañantes ayudarán sin sustituir la acción del Espíritu Santo en el alma.

La aspirante antes de su consagración completará su plan de formación, fijado por el obispo, que será personal según su edad, bagaje formativo y proceso vital; uniformizar de forma rígida esta formación no parece lo más adecuado dada la elasticidad, plasticidad y flexibilidad de esta vocación, que se caracteriza por la falta de carisma fundacional.

Este periodo de formación, abarcará de ordinario cinco años, dos años de formación propedéutica y tres años de formación teológica en los que la candidata consolidará su preparación; para ello se la animará a asistir a cursos de estudios en las facultades teológicas e institutos de ciencias religiosas.

La formación propedéutica $(E S I, 92)$ tendrá como finalidad conocer los aspectos esenciales de la consagración y forma de vida del Ordo virginum para poder confrontarlos con su propia intuición vocacional; la formación teológica $(E S I, 102)$ se extenderá al campo de la antropología cristiana, Biblia, liturgia e historia de la vida consagrada, con referencia particular al Concilio Vaticano II y a las intervenciones recientes del Magisterio eclesial.

15 Moschetii, 153. 
El obispo podrá designar un delegado (un sacerdote de la diócesis) o delegada (una virgen consagrada) para coordinar esta función, pero sin desentenderse de ellas, por lo que son convenientes durante este proceso los encuentros periódicos con la candidata y no dejar el escrutinio final para fechas cercanas a la ceremonia.

«Podrá nombrar un Delegado, elegido preferentemente del presbiterio diocesano, o una Delegada propia, escogida preferiblemente entre las vírgenes consagradas de la Diócesis, para la atención pastoral del Ordo Virginum, definiendo los ámbitos de su condición y sus competencias específicas» $(E S I, 50)$.

Respecto a la posibilidad que tiene el obispo de designar alguien que le ayude, considero que la función del delegado o delegada no son equiparables, ya que el primero es sacerdote (lo que puede favorecer que la candidata comparta con él temas de conciencia o de fuero interno), y la segunda es una virgen ya consagrada (que puede orientar en cuestiones prácticas externas), hecho que influirá en el clima de los encuentros y conversaciones que produzcan.

El obispo y la candidata mantendrán entrevistas periódicas en las que se producirán los escrutinios, donde la aspirante hará una relectura de su historia, le irá informando acerca de su pasado y de su presente, para llegar a saber si este es su verdadero camino, y descubrir sus potenciales que marcarán su futura labor apostólica. Según el c. 630, 5,

«Los miembros deben acudir con confianza a sus superiores, a quienes pueden abrir su corazón libre y espontáneamente. Sin embargo, se prohíbe a las Superiores inducir de cualquier modo a los miembros para que les manifiesten su conciencia».

El obispo es el que verifica si la candidata reúne los requisitos, y previa petición de esta por escrito autógrafo $(E S I, 104)$, indicando el parecer del acompañante espiritual, será quien la admita o no a la consagración; las intromisiones al respecto de otras vírgenes consagradas estarán fuera de lugar y deberán ser evitadas, ya que implican una violación de la conciencia, que es tierra sagrada.

En algunos casos puede resultar útil recurrir a expertos en ciencias psicológicas $(E S I, 90)$, con el consenso previo de la persona interesada, que ha de ser libre, consciente y estar expresado por escrito, salvaguardando siempre el derecho a la intimidad según canon 220 CIC: «A nadie 
le es lícito lesionar ilegítimamente la buena fama de que alguien goza ni violar el derecho de cada persona a proteger su intimidad».

El derecho a la intimidad es un derecho natural y fundamental cuya titularidad corresponde a la persona por el solo hecho de serlo, constitutivo de la dignidad humana; un derecho de la personalidad configurado en sentido negativo consistente en la prohibición de intromisiones no autorizadas en el ámbito propio y más íntimo de la persona. Es un derecho subjetivo que la Iglesia solo puede entrar a regular como instrumento al servicio del destino de toda persona bautizada, que es la salvación del alma ${ }^{16}$.

Así pues, en modo alguno será aceptable que el obispo, delegado u otras vírgenes, bajo pretexto de salvaguardar la identidad de la vocación recién restaurada, sonsaquen información, a modo de cuenta de conciencia, a la mujer que se acerca interpelada por este modo de vida.

No obstante, el obispo recogerá las informaciones oportunas de aquellos que han acompañado el camino de la candidata (delgado/delegada), excepto las que podría aportarle el acompañante espiritual (ESI, 104), acerca de su parecer sobre si está preparada para ser consagrada; en todo caso es decisión del obispo admitir o no admitir a la aspirante a la consagración.

Aproximación, formación y escrutinio final $(E S I, 81)$ son tres fases del proceso, sabiendo que no conviene apresurarse ya que el compromiso es definitivo, irrevocable e irrepetible que, aunque no imprime carácter, es una donación permanente en totalidad (cuerpo y alma) que tiene condición no de sacramento, pero sí sacramental.

\subsubsection{El obispo como sujeto que consagra}

Nadie puede consagrarse a sí mismo, hacerse santo, sagrado, de Dios; de nuevo acudo al término latino consecratur en voz pasiva, que significa ser consagrada; la consagración es un acto de Dios sobre la criatura, no es la virgen la que se presenta, es la Iglesia la que presenta a la virgen.

${ }^{16}$ Miguel Campo, "Derecho a la intimidad y recurso a la psicología en el proceso de admisión y formación de candidatos al sacerdocio. Comentario canónico al documento de la congregación para la educación católica: orientaciones para el uso de las competencias del uso de la psicología en la admisión y formación de los candidatos al sacerdocio", Estudios Eclesiásticos 89 (2014): 652-656. 
En la Iglesia por razones históricas jamás ha cedido la consagración de vírgenes a ningún superior que no sea obispo diocesano ${ }^{17}$. El obispo diocesano es el ministro ordinario de la consagración, que no podrá celebrarse en sede vacante y solamente en caso de verdadera necesidad recurrirá a delegar la facultad de celebrarla (ESI, 47).

Cabría preguntarse si el obispo puede delegar esta facultad en un sacerdote o si se requiere que sea un obispo el que consagre a la virgen. Sin embargo, teniendo en cuenta que la Instrucción, en cuanto norma de desarrollo, no puede contradecir al Código de Derecho Canónico, que explícitamente señala que las vírgenes «son consagradas a Dios por el obispo diocesano» ${ }^{18}$, considero que la tradición y densidad del rito requieren de la presencia de un obispo como ministro consagrante, designado por la Iglesia como el esposo, para la validez de la consagración.

\subsubsection{Consagración litúrgica de especiales características y efectos}

En cuanto a las características, nos encontramos ante una consagración litúrgica de carácter nupcial simbolizada con el velo, que era la insignia más característica de la virgen, como también lo era de la mujer casada; con posterioridad, cuando el anillo pasó a ser el signo más destacado del matrimonio, la Iglesia lo convirtió en signo esponsal de la virgen consagrada.

Es una consagración solemne, que no significa que haya de hacerse con boato ante la presencia de un número importante de personas; se trata de una noción canónica, que deriva de la solemnidad de la oración consagratoria ante un número de testigos, y de sus efectos: queda convertida toda su persona en sagrada y en consecuencia no puede dedicarse a uso profano; «escogida y puesta aparte en el pueblo de Dios, la virgen es devuelta al pueblo como criatura nueva» ${ }^{19}$.

Esta consagración tiene carácter público, lo que no quiere decir que tenga que pregonar que ha sido consagrada, sino que ha de vivir su consagración con prudencia, sin alardear; será con ocasión de las reuniones eclesiales: retiros, convivencias, jornadas de formación, donde la virgen podrá explicar con más claridad su vocación.

17 Ritual de Consagración de vírgenes 17, Madrid 1979.

18 CIC, 604.

19 Moschetii, 63. 
La ceremonia se celebra normalmente en la catedral (cabe hacerlo en otras iglesias o capillas) en un día festivo o solemnidad de la Virgen, anunciando previamente la ceremonia.

En cuanto a efectos, se trata de una consagración perpetua, irrevocable e irrepetible ${ }^{20}$, que perfecciona la consagración bautismal; esta ceremonia implica una bendición constitutiva, y lleva consigo una donación permanente, que no puede repetirse ya que es indeleble.

Es una forma estable de vida por lo que la virgen no puede desconsagrarse, aunque sí puede acudir al obispo diocesano, presentando una solicitud escrita para ser dispensada de las obligaciones derivadas de su consagración (ESI, 70); por su consagración, la virgen deviene una persona sagrada que no podrá dedicarse a usos vanos y profanos; ahí radica la grandeza del acto que sobrepasa el pensamiento humano.

\subsubsection{Vinculación a la diócesis}

La vinculación de la virgen con la diócesis es esencial y puede estar originada por la residencia, el ejercicio de la labor profesional dentro de los límites jurisdiccionales de la diócesis o por el vínculo espiritual (p. ej., porque de forma habitual se desplace allí por motivos de afinidad para su formación, actos litúrgicos, obras de apostolado). Como afirma una autora, «el vínculo que se establece entre la virgen y el obispo de su diócesis es de naturaleza litúrgica y mística ${ }^{21}$.

La dimensión escatológica no implica que la virgen se desentienda de las realidades temporales o que las menosprecie; al contrario, debe vivir en el mundo con el estilo de quien ha sido enviado a vivir su existencia como anticipo de la vida eterna, como caminante hacia la ciudad celeste; la virgen por su consagración es signo trascendente del amor de la Iglesia a Cristo, imagen escatológica de la Esposa celeste y de la vida futura ${ }^{22}$.

Al respecto me gustaría hacer notar que algunos obispos, en el ejercicio de su discrecionalidad, se han negado a consagrar vírgenes por el temor a asumir una responsabilidad sobre ellas, lo que me parece desafortunado ya que los beneficios de la consagración (la Gracia de la

\footnotetext{
${ }^{20}$ Gloria Irene Álvaro, Amar y servir (Salamanca: Secretariado Trinitario, 2004),

21 Moschetii, 119.

22 Ritual de Consagración de vírgenes, prenotando 1, Madrid 1979.
} 13. 
consagración atraerá nuevas gracias) no son solo personales, sino también para la iglesia particular y universal.

En el caso de que la virgen consagrada cambie su residencia a otra diócesis, o a otro país, necesitará el permiso del obispo de la diócesis en que fue consagrada $a$ quo, y ser recibida por el obispo de la diócesis a la que se traslada ad quem (ESI, 62); en este sentido la vinculación es similar a la que mantienen los ministros ordenados con su obispo; podemos decir que la virgen queda «cuasi incardinada» en una diócesis.

La consagración para tener efectos jurídicos deberá anotarse en el libro del obispado $(E S I, 51)$ y en la nota marginal del libro parroquial donde la virgen fue bautizada, como ocurre con la celebración del matrimonio; esto implica que la diócesis tiene que comunicar este hecho a la parroquia (perteneciente a la diócesis o no) en que fue bautizada, aunque de facto no se venga haciendo por acumulación de tareas.

\section{CONCLUSIONES}

De lo señalado anteriormente, se derivan las siguientes conclusiones.

1. En cuanto a su naturaleza, se trata de una vocación únicamente femenina (ya que es la mujer la que mejor refleja la imagen de la Iglesia como esposa), donde el peso de la tradición es muy fuerte, de marcado carácter esponsal que se materializa con un vínculo definitivo. Lo esencial de la virgen consagrada es lo que es (una mujer orante de mirada contemplativa) y no lo que hace.

Es un camino personal, aunque no particular; el Ordo virginum se caracteriza por su falta de carisma fundacional, es una vocación caracterizada por su plasticidad, por ser muy moldeable. Es una llamada de Dios individual, que reúne a personas que en su individualidad se agrupan para llevarla a mejor término.

Al tratarse de un camino personal, se tendrá que buscar un equilibrio entre la homogeneidad y la plasticidad, huyendo de individualismos egocéntricos, pero respetando la identidad de la aspirante (las hay más apostólicas, las hay más contemplativas) con la posibilidad de que cada una siga la espiritualidad que más le atrae: franciscana, carmelitana, etc.

La virgen consagrada, como esposa fecunda, ejercerá su maternidad espiritual a través de sus ministerios: dirigiendo talleres de oración, 
realizando un acompañamiento espiritual, desempeñando labores en la pastoral de enfermos, impartiendo catequesis en la parroquia, etc. Por lo general compaginarán su trabajo profesional con su misión apostólica, aunque a algunas de ellas la Iglesia les pida que dediquen todo su tiempo a trabajar para ella en diferentes organismos: Conferencia Espiscopal, obispado, tribunal eclesiástico.

2. Relativo a su regulación, contamos con el Ritual de consagración de 1970, el Código de Derecho Canónico de 1983, que le dedica un canon (604), y la Instrucción recientemente promulgada en junio de 2018 Ecclesiae Sponsae Imago, que ha aclarado puntos acerca de los requisitos de admisión, el arraigo a la diócesis y el plan de formación.

El código señala que se asemeja (podríamos decir que se acerca) a una forma de vida consagrada, no formando parte de los Institutos de Vida Consagrada, debido a que solo emiten un propósito de castidad, sin profesar los consejos evangélicos, aunque incluya de forma implícita una vida alejada del lujo y ostentación, y una vida obediente, derivada de su vinculación al obispo de la diócesis en la que han sido consagradas.

De igual manera, no forma parte de su esencia la vida en común (sí fraterna por compartir una misma vocación), aunque puedan asociarse o compartir vivienda, pero no al estilo de casa religiosa dotada de estructura jerárquica, sino como hermanas en plano de igualdad que conviven por propia voluntad de forma temporal o definitiva.

Las vírgenes no se consagran, sino que son consagradas. La mujer emite de forma pública un propósito de castidad que previamente habrá realizado de forma privada, recibiendo por parte de la Iglesia un reconocimiento de este estado, mediante una consagración pública, que la convierte en una persona nueva (sagrada) a través de un rito litúrgico aprobado por la Iglesia. Desde siempre ha habido vírgenes, unas han sido consagradas, y otras simplemente se han consagrado privadamente. Solo las primeras tienen el estatus de virgen consagrada.

3. Referente a los requisitos de admisión en el Ordo Virginum, que son abordados en los preliminares del Ritual de consagración y en la Instrucción Ecclesiae Sponsae Imago, son un mínimo exigible que, conforme al canon 18, han de ser interpretados de forma estricta; en modo alguno pueden ser interpretados de forma extensiva, ya que sería una interpretación odiosa.

Así pues, la mujer no puede haber tenido un esposo previo, ni de hecho ni de derecho; de ahí que no sean consideradas aptas las que hayan 
contraído nupcias previas, o hayan vivido en situación asimilada al matrimonio, o en un estado de convivencia de hecho pública o notoria, divulgada, alardeada. Me refiero a la situación de more uxorio que no se identifica con integridad física, sino con virginidad en cuanto a estado. Recordemos que la Iglesia ha reconocido tradicionalmente tres estados: casado, viudo o virgen.

4. En relación al discernimiento, previamente a la consagración el obispo (en su caso el delegado/a) y la candidata fijarán un itinerario para verificar su idoneidad, que garantice la perseverancia de la mujer en su propósito. Deberá cumplir un plan de formación que puede prolongarse hasta cinco años (dos años de formación propedéutica, tres años de formación teológica).

De ahí que se desaconsejen las consagraciones precipitadas y que se analice la madurez humana (no se consagran menores de 25 años) y espiritual de la candidata; la prudencia que le haga capaz de evitar peligros; sus buenas costumbres, de manera que su forma de vida sea concorde a su consagración; que tenga un medio de vida que le sirva de sustento (no pueden suponer una carga para la diócesis); una formación permanente tras ser consagrada y una regla de vida supervisada por el director espiritual, elementos todos que presentará al obispo solicitando su aprobación.

Tampoco puede constituir el Ordo virginum una solución para las mujeres provenientes de la vida consagrada que, por diversos motivos, no hayan podido perseverar en su orden o congregación, encontrándose desubicadas. Diferente es que se produzca una segunda llamada de Dios, tras la primera que fue fallida. Se constata que Dios no retira sus dádivas y que se adapta a nuestras circunstancias, repitiendo su invitación al seguimiento una y otra vez.

El discernimiento se llevará a cabo en las reuniones periódicas que mantiene el obispo con la aspirante en el periodo de formación, a través de los llamados escrutinios. No son aceptables las intromisiones de ningún tipo de terceras personas (delegados, vírgenes ya consagradas), utilizando métodos cuestionables, sonsacando información sobre la vida pasada, bajo excusa de celo por proteger esta vocación; entrevistas que deben continuar una vez consagrada, al menos una vez al año, para que se concrete y mantenga la vinculación a la diócesis y evitar dispersiones.

Al ser una vocación a la vez antigua y nueva, considero que sería oportuno que, sin olvidar sus orígenes (las primeras vírgenes de la cristiandad), el Ordo virginum encuentre su lugar en el siglo XXI para que 
en él tengan cabida mujeres de nuestro tiempo (las segundas vírgenes tras el Concilio). Las primeras manifestaron el deseo de ser consagradas, las segundas lo han recuperado para bien de su Iglesia. Unas y otras tienen igual relevancia, a las continuadoras les toca la misión de conservarlo, adaptarlo y mejorarlo si cabe.

La realidad nos muestra que hoy en día la mujer entra y sale, se forma y trabaja, se relaciona con personas de ambos sexos, mantiene relaciones de amistad, y noviazgo, atraviesa periodos de discernimiento en su vida, lo que no es un obstáculo para que, con posterioridad, abrace el Ordo virginum, si cumple los requisitos que marca la ley.

Ya no se trata de mujeres recluidas en casa, dedicadas únicamente a la oración, santas lecturas y obras de caridad; ahora el Ordo virginum cuenta con mujeres en el ámbito profesional de la enseñanza, de la educación, de la empresa, incluso de la política, que mantienen su lámpara encendida, iluminando con ella las realidades terrenas, siendo testimonio del amor esponsal de Cristo a su Iglesia.

\section{REFERENCIAS}

FUENTES

CIVCSVA. Instrucción Ecclesiae Sponsae Imago, 8 junio 2018, http:// www.vatican.va/roman_curia/congregations/ccscrlife/documents/ rc_con_ccscrlife_doc_20180608_istruzione-ecclesiaesponsaeimago_ sp.html

Juan Pablo II. "Código de Derecho canónico, 25 enero 1983". AAS 75II (1983): 1-301.

Ritual de Consagración de vírgenes, Madrid 1979.

Autores

Álvarez Alonso, Carmen. "Orden de las Vírgenes". En Diccionario General de Derecho Canónico $V$, dirigido por Jorge Otaduy, Antonio Viana, y Joaquín Sedano, 745-747. Cizur Menor: Thomsom Reuters - Aranzadi, 2012.

Álvaro, Gloria Irene. Amar y servir. Salamanca: Secretariado Trinitario, 2004. 
Burke, Raymond Leo. "Lex orandi, lex credendi. El rito de la consagración y la vocación de la virginidad consagrada en el mundo". En Virginidad consagrada en el mundo. Un don para la Iglesia y en la Iglesia. Actas del III Congreso Internacional del Orden de las Vírgenes celebrado en Roma, mayo 2008, editado por Lourdes Grosso García, 43-72. Madrid: Edice, 2010.

Campo, Miguel. "Derecho a la intimidad y recurso a la psicología en el proceso de admisión y formación de candidatos al sacerdocio. Comentario canónico al documento de la congregación para la educación católica 'orientaciones para el uso de las competencias del uso de la psicología en la admisión y formación de los candidatos al sacerdocio"'. Estudios Eclesiásticos 89 (2014): 635-673.

Hourcade, Janine. Una Vocación femenina recuperada: El Orden de las vírgenes consagradas. Salamanca: Secretariado Trinitario, 2003.

Moschetti, Paola. El Ordo Virginum. Germen de la vida cristiana. Salamanca: Secretariado Trinitario 2012.

Rincón, Tomás. "Comentario al 604". En Comentario Exegético al Código de Derecho Canónico, dirigido por Antonio Marzoa, Jorge Miras, y Rafael Rodríguez-Ocaña, 1497-1498. Pamplona: Eunsa 1996.

Vizmanos, Francisco de Borja. Las vírgenes cristianas de la Iglesia primitiva. Madrid: BAC 2009. 